\title{
TBDY 2018 ve Mander Modeline göre Sargılı Betonun Gerilme-Şekil Değiştirmesinin Araştırılması
}

\author{
Saeid FOROUGHİ1 ${ }^{1 a^{*}}$, Rohullah JAMAL ${ }^{1 \mathrm{~b}}$, Süleyman Bahadır YÜKSEL ${ }^{1 \mathrm{c}}$ \\ Konya Teknik Üniversitesi, Mühendislik ve Doğa Bilimleri Fakültesi, İnşaat Mühendisliği Bölümü, Konya, \\ Türkiye \\ saeid.foroughi@yahoo.com
}

Received/Geliş: 31.08 .2020

Accepted/Kabul: 12.10 .2020

\begin{abstract}
Öz: Bu çalışmada Türkiye Bina Deprem Yönetmeliği 2018 ve Mander modellerine göre sargıllı betonarme kolonların gerilme-şekil değiştirme ilişkileri incelenmiştir. Önerilen sargılı beton modellerine göre betonarme kolonlar için sargılı beton basınç dayanımı ve gerilme-şekil değiştirme ilişkileri araştırılmıştır. Sargılı betonun davranışının daha iyi anlaşılabilmesi için gerilme-şekil değiştirme bağıntıları ve sargılı beton modelleri hakkında bilgi verilmiştir. Sargılı betonun davranışını araştırmak için farklı sargı donatı çapı ve farklı sargı donatı aralığına sahip kare en-kesitli betonarme kolon modelleri tasarlanmıştır. Sargı donatısı çapının ve aralıklarının sargılı beton basınç dayanımına etkisi araştırılmıştır. Kare en-kesitli kolonların farklı sargılı beton modelleri dikkate alınarak gerilme-şekil değiştirme ilişkileri araştırılarak karşılaştırılmıştır. Tasarlanan kare en-kesitli kolon modellerinde sargılı beton basınç dayanımları ve basınç birim şekil değiştirmeleri hesaplanarak gerilmeşekil değiştirme grafikleri elde edilmiştir. Analiz sonuçlarından elde edilen sonuçlar farklı parametrelere göre karşılaştırılarak yorumlanmıştır. TBDY 2018 ve Mander modeli ile elde edilen sonuçlar karşılaştırılarak yorumlanmıştır. Modellerde farklı çaplarda ve aralıklarda sargı donatısı kullanımının, farklı parametrelerde tasarlanan betonarme kolon kesitlerinde çekirdek betona uygulanan etkili yanal basınçları ve sargılı beton basınç dayanımlarını etkilediği sonucu elde edilmiştir.
\end{abstract}

Anahtar Kelimeler: Betonarme kolon, Basınç dayanımı, Gerilme-şekil değiştirme, Sargılı beton, Sargı Donatı.

\section{Investigation of Stress-Strain Variation of Confined Concrete According to TBEC 2018 and Mander Model}

\begin{abstract}
In this study, stress-strain relationships for confined reinforced concrete columns were investigated according to TBEC 2018 and Mander models. Confined concrete compressive strength and stress-strain relationships have been investigated for concrete columns according to the proposed confined concrete models. In order to better understand the behavior of the confined concrete, stress-strain relations and information about the confined concrete models are given. To investigate the behavior of confined concrete, square cross-section reinforced concrete column models with different transverse reinforcement diameters and spacing have been designed. The effect of the diameter and spacing of the transverse reinforcement on the confined concrete compressive strength was investigated. Stress-strain relations of square cross-section columns were investigated by considering the different confined concrete models. The stress-strain curves were obtained by calculating the confined concrete compressive strengths and strain at maximum concrete stress in the square cross-section column models designed. The results obtained from the analysis results were compared and interpreted according to different parameters. Results obtained with TBEC 2018 and Mander model were compared and interpreted. It has been concluded that the use of transverse reinforcement with different diameters and spacing in the models affects the lateral confining stress on core concrete from transverse reinforcement and compressive strength of confined concrete in column sections designed with different parameters.
\end{abstract}

Keywords: Reinforced concrete column, Compressive strength, Stress-strain, Confined concrete, Confining Reinforcement

Foroughi, S., Jamal, R., Yüksel, S. B., “TBDY 2018 ve Mander Modeline göre Sargılı Betonun Gerilme-Şekil Değisştirmesinin Araştırılması” El-Cezerî Fen ve Mühendislik Dergisi 2021, 8(1); 363-375. 


\section{Giriş}

Betonarme kolonlar, yanal sertliğe de katkıda bulunan her türlü yapıdaki ana yük taşıyıcı elemanlardır. Betonarme kolonun gerilme-şekil değiştirme davranışı, moment eğrilik analizi ile kolonun sünekliğini hesaplamak için önemlidir. Betonarme kolonların sargı donatısı, özellikle depreme maruz kaldıkları durumlarda sargı etkisi ile kolonların dayanım ve sünekliğinin artırmasında önemli rol oynar. Betonarme kolonlarda sargı donatısı boyuna donatının yerel burkulmasını geciktirmek, kesme kuvvetine karşı koymak, ani kesme kırılmasını önlemek ve sarg1 etkisi ile dayanım ve sünekliği artırmak için kullanılır [1]. Sargı donatılı betonarme elemanların mukavemet ve süneklik kapasitelerini değerlendirmek için gerilme-ş̧ekil değiştirme davranışının doğru bir şekilde modellenmesi gereklidir [2]. Sarg1 donatılı betonarme elemanlardaki şekil değiştirme çatlama sınırına ulaştığında, yanal gerilmelerin artması ile sargı donatılarının etkisi ortaya çıkar. Bu noktadan itibaren, sargı donatısı çekirdek betonuna yanal basınç uygulaması ile beton aktif bir sargılı malzeme davranışı göstermektedir [3]. Sargılı betonun gerilme-şekil değiştirme ilişkisi, elastik bir bölge ve ardından doğrusal olmayan bir eğri ile tanımlanır. Sargı donatının rijitliği ve davranışı, betonun davranışını etkileyen önemli faktörlerdir [4]. Sargı donatı dayanımı, sargılı betonarme elemanların mukavemetini ve sünekliğini önemli ölçüde artırabilir. Bununla birlikte, sargı donatı dayanımı çekirdek betonun yanal basıncı ile ilişkilidir [5]. Sargılı betonarme elemanın gerilme-şekil değiştirme ilişkisi, sargı donatıların akmasına kadar artış dalı, ardından pekleşme dalı ve sargının etkinliği ile ilgili bir eğim ile karakterize edilir [6].

Betonarme elemanların doğrusal olmayan davranışlarının doğru tahmini, sismik yükler altında binaların kapasitesinin güvenilir bir tahminini sağladığı için her zaman çekici bir çalışma konusu olmuştur. Malzeme modeli ve tasarım parametreleri betonarme kolonların doğrusal olmayan davranışını etkilemektedir [7]. Betonarme yapıların ve yapısal elemanların davranışı, elemanların gerilme-şekil değiştirme ve deformasyon özelliklerine bağlı olarak değişir. Sargılı beton davranışının belirlenmesinde farklı araştırmacılar tarafından çok sayıda deneysel ve kuramsal çalışma ve davranış modeli önerilmiştir. Sargılı beton davranışı ile ilgili geliştirilen model, Mander ve arkadaşları [8] tarafından yapılan çalışmalara dayanmaktadır. Önerilen davranış modeli spiral veya dairesel etriye ile sarılmış kesitlerde, kare ve dikdörtgen kesitlerde, her iki yönde de farklı sayıda ve miktarda etriye ve/veya çiroz bulunan kesitlerde kullanılabilmektedir. Doğrusal olmayan yöntemler ile şekil değiştirmeye göre değerlendirmede, başkaca bir modelin seçilmediği durumlarda kullanılmak üzere, sargılı ve sargısız beton için Türkiye Bina Deprem Yönetmeliği 2018'de [9] gerilme-şekil değiştirme bağıntıları tanımlanmıştır.

Çevrimsel yükler altındaki betonarme kesitler büyük şekil değiştirmelere maruz kaldıklarında yük taşıma kapasitelerini çekirdek içerisinde kalan sarılmış betonun davranışı belirler. Sargı donatılı kolonların davranışını açıklamak için geliştirilmiş olan literatürde bulunan analitik modeller betonun gerilme-şekil değiştirme eğrisinin maksimum yükten sonraki yumuşama kısmını da tanımlamaktadır. Bu modellerde genel olarak dikkate alınan faktörler sırasıyla yatay donatı miktarı, beton ve çelik mukavemeti, boyuna ve enine donatının kesitteki dağılımı, etriye aralığı ve kesit boyutlarıdır [10].

Yüksel ve Foroughi [11]; kare kesitli betonarme kolonların çekirdek bölgesinin gerilme-şekil değiştirme davranışını analitik olarak araştırılmışlardır. Çalışmalarında Mander [8], TBDY [9] Saatçioğlu ve Ravzi [12] tarafından sargilı betonarme elemanlar için önerilmiş olan eksenel yük altındaki davranış modelleri incelenmiştir. Farklı parametrelere sahip betonarme elemanların sargı etkinlik değerleri, sargı donatısı tarafından çekirdek betonuna uygulanan gerilmeler, sargılı betonda beton basınç gerilmesi ve basınç birim şekil değiştirme değerleri araştırılmıştır. Betonarme kolon modellerinde Mander [8], TBDY [9] Saatçioğlu ve Ravzi [12] modellerine göre sargılı beton basınç dayanımları ve basınç birim şekil değiştirmeleri hesaplanarak gerilme-birim şekil değiştirme ilişkileri elde edilmiş ve elde edilen sonuçlar farklı parametrelere göre karşıllaştırılmıştır. 
$\mathrm{Bu}$ çalışmada sargı donatısının sargılı betonun basınç dayanımına ve gerilme-şekil değiştirme ilişkisine etkisini araştırmak için [10] yaptıkları çalışmaya ilaveten üç farklı sargı donatısı ve 11 farklı sargı donatı aralığı dikkate alınmıştır. Çalışmada ilk olarak doğrusal elastik olmayan davranışın daha iyi anlaşılabilmesi için gerilme-şekil değiştirme bağıntıları, Mander [8] ve TBDY [9] tarafından sargılı betonarme elemanlar için önerilmiş modeller hakkında bilgi verilmiştir. Mander [8] ve TBDY [9] sargılı beton modelleri kullanılarak sargilı betonarme yapısal elemanların davranışı dikkate alınarak sargılı beton basınç dayanımı elde edilerek karşılaştırılmıştır. Farklı parametrelerde sargılı beton modellerinde sargılı beton basınç dayanımları hesaplanarak gerilmebirim şekil değiştirme ilişkileri elde edilmiş ve elde edilen sonuçlar farklı parametrelere göre karşılaştırılarak yorumlanmıştır. Farklı parametrelerde toplam 33 adet betonarme kare kolon modeli tasarlanmıştır. Betonarme kolon modellerinin tasarımında TBDY'de [9] verilen hükümler dikkate alınmıştır.

\section{Gerilme- Şekil Değiştirme Bağıntıları}

Deprem etkileri altındaki betonarme yapısal elemanlar büyük şekil değiştirmelere maruz kaldıklarında yük taşıma kapasitelerini sargı donatısı arasında kalan çekirdek betonun davranışı belirler. Sargı donatıları ile sarılmış betonarme yapısal elemanların davranışını araştırmak için Mander [8] ve TBDY [9] modeli kullanılmıştır.

\subsection{Sargılı Beton için Mander Modeli}

Mander [8] beton modeli, dairesel, spiral, dikdörtgen sarg1 donatıl1, dairesel, kare veya dikdörtgen kesitli betonarme yapı elemanların monotonik veya çevrimsel yükler altındaki davranışlarını tanımlamak amacıyla geliştirilmiştir. Mander [8] dairesel, spiral, dikdörtgen sargı donatısı ile sarılmış betonarme kesitler için gerilme-birim şekil değiştirme bağıntısı önermiştir. Mander [8] beton modeline göre sargılı ve sargısız betonun gerilme-şekil değiştirme grafiği Şekil 1'de verilmiştir. Mander [8] modeline göre sargılı kolonun etkili olarak sarılan kesit görünümü Şekil 2'de verilmiştir.

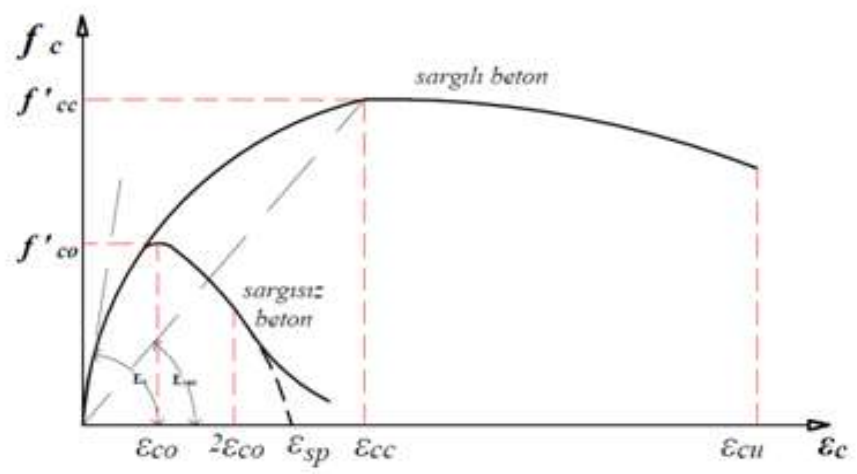

Şekil 1. Monotonik yükler altındaki sargılı ve sargısız beton gerilme-şekil değiştirme grafiği [8]

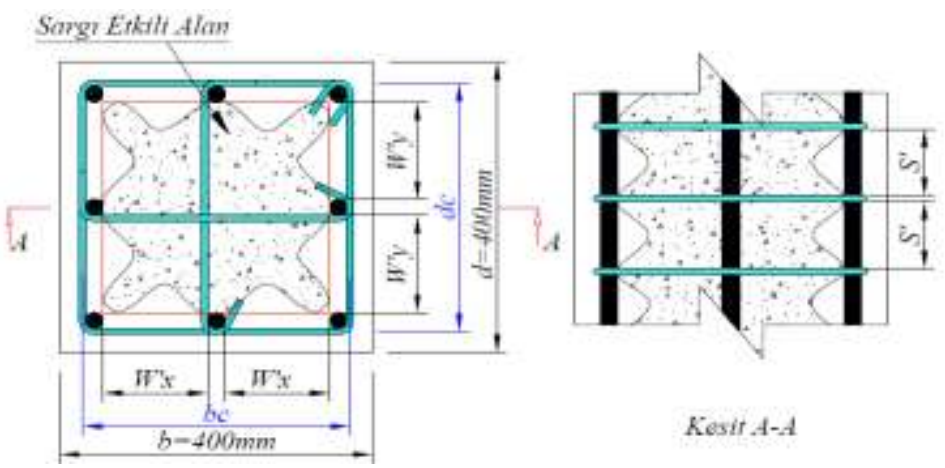

Şekil 2. Mander modeline göre sargılı betonun kesit görünüşü 
Etkili olarak sarılan kesit alanı $\left(A_{e}\right)$ Denklem (1) ile hesaplanmaktadır. Denklemde $b_{c}$ ve $d_{c}$; çekirdek betonunu sargilayan etriyelerin eksenleri arasında kalan kesit boyutu, $s^{\prime}$; boyuna doğrultuda etriyelerin net aralığı ve $w_{i}^{\prime}$ bir etriye kolu veya çiroz tarafindan mesnetlenen boyuna donatıların arasındaki net uzaklığı göstermektedir.

$$
A_{e}=\left(b_{c} d_{c}-\sum_{i}^{n} \frac{\left(w_{i}^{\prime}\right)^{2}}{6}\right)\left(1-\frac{s^{\prime}}{2 b_{c}}\right)\left(1-\frac{s^{\prime}}{2 d_{c}}\right)
$$

Etkili olarak sarılmış olan alanın $\left(A_{e}\right)$, sargılı betonun net en-kesit alanına $\left(A_{c c}\right)$ oranı $\left(k_{e}\right)$ Denklem (2) ile hesaplanmıştır. $k_{e}$ sargı etkisi katsayısıdır.

$$
k_{e}=\frac{A_{e}}{A_{c c}}
$$

Toplam enine donatının hacimsel oranı Denklem (3) ile hesaplanmıştır. Denklemde; $A_{s x}$ ve $A_{s y} x$ ve $y$ yönlerinde kullanılan sargı donatılarının en-kesit alanı ve $\rho_{x}$ ve $\rho_{y}, x$ ve $y$ yönlerinde kullanılan yönlerde sargı donatısı oranıdır.

$$
\rho_{s}=\rho_{x}+\rho_{y}=\frac{A_{s x}}{s d_{c}}+\frac{A_{s y}}{s b_{c}}
$$

Çekirdek betonuna uygulanan etkili yanal basınç kuvveti $\left(f_{l}^{\prime}\right)$ Denklem (4) ile hesaplanmaktadır. $f_{y h}$ sargı donatısı akma dayanımıdır.

$$
f_{l}^{\prime}=\frac{1}{2}\left(k_{e} \frac{A_{s x}}{s^{\prime} d_{c}} f_{y h}+k_{e} \frac{A_{s y}}{s^{\prime} b_{c}} f_{y h}\right)
$$

Sargılı beton basınç dayanımı $\left(f_{c c}^{\prime}\right)$ Denklem (5) ile hesaplanmaktadır. $f_{c o}^{\prime}$ sargısız beton dayanımidir.

$$
f_{c c}^{\prime}=f_{c o}^{\prime}\left(-1.254+2.254 \sqrt{1+\frac{7.94 f_{l}^{\prime}}{f_{c o}^{\prime}}}-2 \frac{f_{l}^{\prime}}{f_{c o}^{\prime}}\right) M P a
$$

Sargılı beton basınç gerilmesi $f_{c}$, basınç birim şekil değiştirmesi $\varepsilon_{c}$ 'nin fonksiyonu olarak Denklem (6) ile hesaplanır.

$$
f_{c}=\frac{f_{c c}^{\prime} x r}{r-1+x^{r}}
$$

$f^{\prime}{ }_{c c}$ 'ye karşı gelen birim kısalma $\left(\varepsilon_{c c}\right)$ Denklem (7)'de tanımlanmıştır. $\varepsilon_{c o}$ normal dayanımlı betonlar için yaklaşık olarak 0.002 olarak önerilmiştir. Normalize edilmiş beton birim şekil değiştirmesi $x$ ile $r$ değişkenine ilişkin bağıntılar Denklem (8)'de verilmiştir.

$$
\begin{gathered}
\varepsilon_{c c}=\varepsilon_{c o}\left[1+5\left(\frac{f_{c c}^{\prime}}{f_{c o}^{\prime}}-1\right)\right] \\
x=\frac{\varepsilon_{c}}{\varepsilon_{c c}}, r=\frac{E_{c}}{E_{c}-E_{s e c}}, \quad E_{c}=5000 \sqrt{f_{c o}^{\prime}} M P a \quad, \quad E_{s e c}=\frac{f_{c c}^{\prime}}{\varepsilon_{c c}}
\end{gathered}
$$

Sargılı betondaki maksimum basınç birim şekil değiştirmesi $\varepsilon_{c u}$ Denklem (9) ile hesaplanmaktadır. Denklemde; $f_{y w}$ enine donatının akma dayanımını, $\varepsilon_{s u}$ donatı çeliğinin kopma birim şekildeğiştirmesi, $E_{c}$ betonun elastisite modülü ve $E_{s e c}$ sargılı betonun sekant elastisite modülüdür. 


$$
\varepsilon_{c u}=0.004+\frac{1.4 \rho_{s} f_{y w} \varepsilon_{s u}}{f_{c c}^{\prime}}
$$

\subsection{TBDY (2018) Sargılı Beton Modeli}

Doğrusal olmayan yöntemler ile şekil değiştirmeye göre değerlendirmede, başkaca bir modelin seçilmediği durumlarda kullanılmak üzere, sargılı ve sargısız beton için TBDY'de [9] Şekil 3'te tanımlanan gerilme-şekil değiştirme modeli kullanılmaktadır. TBDY'ye [9] göre sargılı beton modeli için kullanılan parametreler Şekil 4'te verilmiştir.

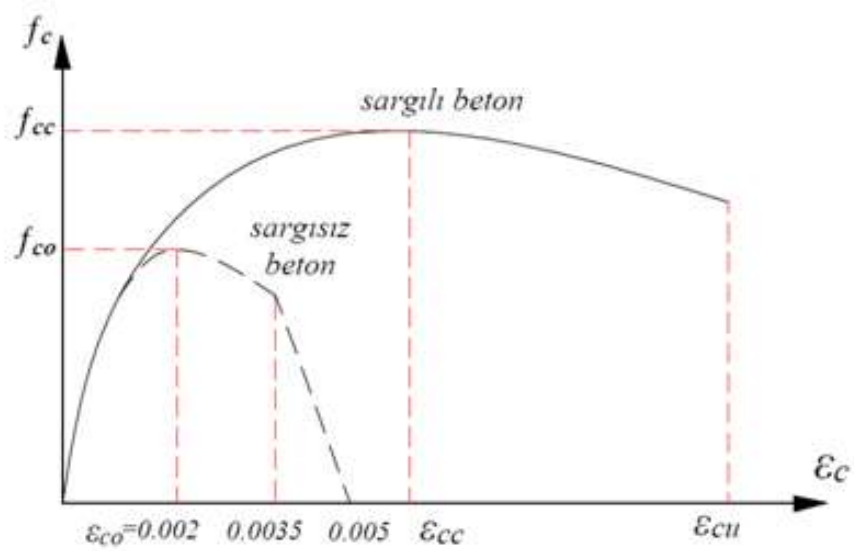

Şekil 3. Sargılı ve sargısız beton için gerilme-şekil değiştirme grafiği

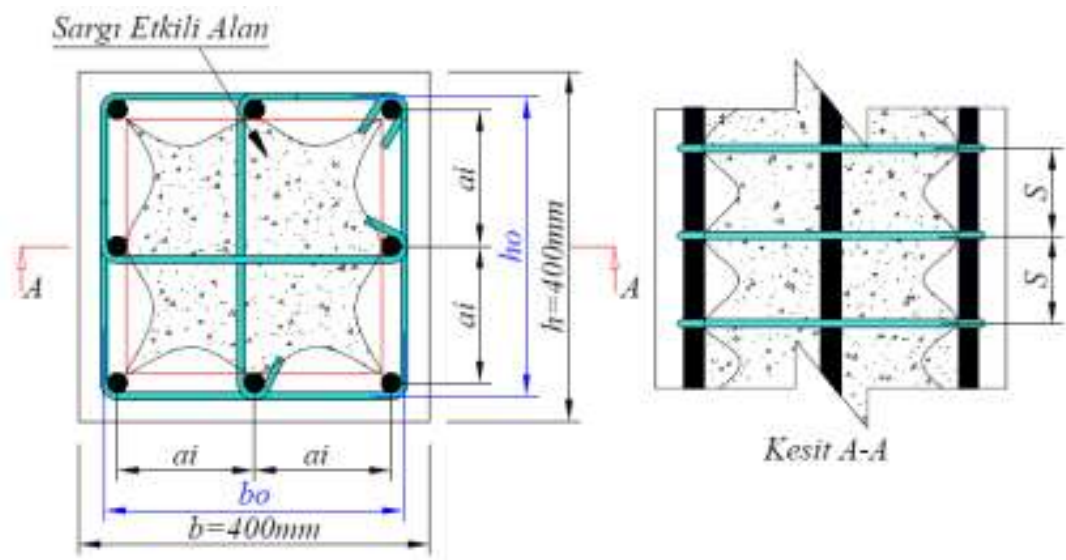

Şekil 4. TBDY (2018)'e göre sargılı beton modeli için kullanılan parametreler

Etkili sargılama basıncı $\left(f_{e}\right)$, dikdörtgen kesitlerde birbirine dik iki doğrultu için Denklem (10)'da verilen değerlerin ortalaması olarak alınmaktadır.

$$
f_{e x}=k_{e} \rho_{x} f_{y w} \quad, \quad f_{e y}=k_{e} \rho_{y} f_{y w} \quad f_{e}=\left(f_{e x}+f_{e y}\right) / 2
$$

Sargılama etkinlik katsayısı $\left(k_{e}\right)$ Denklem (11)’e göre hesaplanmaktadır.

$$
k_{e}=\left(1-\frac{\sum a_{i}^{2}}{6 b_{o} h_{o}}\right)\left(1-\frac{s}{2 b_{o}}\right)\left(1-\frac{s}{2 h_{o}}\right)\left(1-\frac{A_{s}}{b_{o} h_{o}}\right)^{-1}
$$

Sargılı beton modeli; sargısız beton modeli ile bulunan basınç dayanımının etkin sargı basıncının bir fonksiyonu olan $\lambda_{c}$ katsayısıyla çarpılması ila elde edilir (Denklem 12). Sargılı betonda beton basınç gerilmesi $f_{c c}$, Mander [8] tarafından önerilen modelden alınmaktadır. 


$$
f_{c c}=\lambda_{c} f_{c o} \quad, \quad \lambda_{c}=2.254 \sqrt{1+7.94 \frac{f_{e}}{f_{c o}}}-2 \frac{f_{e}}{f_{c o}}-1.254
$$

\section{Materyal ve Metot}

Deprem etkileri altındaki betonarme yapısal elemanlar büyük şekil değiştirmelere maruz kaldıklarında yük taşıma kapasitelerini sargı donatısı arasında kalan çekirdek betonun davranışı belirler. Sargı donatıları ile sarılmış betonarme kolonların davranışını araştırmak için, Mander [8] ve TBDY'de [9] önerilen modeller kullanılmıştır. Betonarme kolon kesitlerine ait tasarım parametrelerinin, kesit davranışına etkisini incelenmek amacıyla farklı parametrelere sahip toplam 33 adet betonarme kolon modeli tasarlanmıştır. Betonarme kolon modellerinin tasarımında TBDY'de [9] verilen hükümler dikkate alınmıştır. Tasarlanan farklı parametrelere sahip betonarme kolonların kesit bilgileri ve betonarme kolon modellerine ait parametreler Şekil 5 ve Tablo 1'de verilmiştir. TBDY'ye [9] göre kolonlarda boyuna donatı alanı, brüt kesitin \%1'inden az, \%4'ünden daha büyük olmayacak şekilde tasarlanmıştır. Kolon modellerinde boyuna donatı $8 \Phi 22 \mathrm{~mm}$ olarak seçilmiştir. Tasarlanan kolon modellerinde üç farklı sargı donatı çapı ( $\Phi 8 \mathrm{~mm}, \Phi 10 \mathrm{~mm}$ ve $\Phi 12$ $\mathrm{mm})$ ve 11 farklı sargı donatı aralığ dikkate alınmıştır $(50 \mathrm{~mm}, 60 \mathrm{~mm}, 70 \mathrm{~mm}, 80 \mathrm{~mm}, 90 \mathrm{~mm}$, $100 \mathrm{~mm}, 110 \mathrm{~mm}, 120 \mathrm{~mm}, 130 \mathrm{~mm}, 140 \mathrm{~mm}$ ve $150 \mathrm{~mm}$ ).

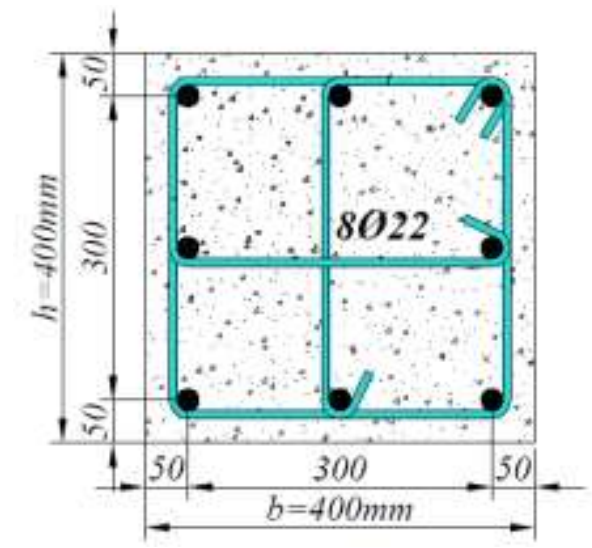

Şekil 5. Parametrik çalışma için tasarlanan kolonların en-kesit boyutları ve donatı yerleşimi

Tablo 1. Tasarlanan betonarme kolon modellerine ait parametreler

\begin{tabular}{|c|c|c|c|c|c|c|c|c|}
\hline \multirow{2}{*}{$\begin{array}{c}\text { Kolon } \\
\text { No }\end{array}$} & \multicolumn{2}{|c|}{$\begin{array}{c}\text { Kesit Boyutları } \\
(\mathbf{m m})\end{array}$} & \multirow{2}{*}{$\begin{array}{c}\text { Boyuna } \\
\text { Donatı }\end{array}$} & \multirow{2}{*}{$\begin{array}{c}\text { Sargı Donatısı } \\
\text { mm }\end{array}$} & \multirow{2}{*}{$\begin{array}{l}\text { Kolon } \\
\text { No }\end{array}$} & \multirow{2}{*}{$\begin{array}{c}\text { Sargi Donatısı } \\
\text { mm }\end{array}$} & \multirow{2}{*}{$\begin{array}{l}\text { Kolon } \\
\text { No }\end{array}$} & \multirow{2}{*}{$\begin{array}{c}\text { Sargi DonatısI } \\
\text { mm }\end{array}$} \\
\hline & $\mathbf{b}$ & $\mathbf{h}$ & & & & & & \\
\hline $\mathrm{C} 1$ & \multirow{11}{*}{400} & \multirow{11}{*}{400} & \multirow{11}{*}{$8 \Phi 22$} & $\Phi 8 / 50$ & C12 & $\Phi 10 / 50$ & $\mathrm{C} 23$ & $\Phi 12 / 50$ \\
\hline $\mathrm{C} 2$ & & & & $\Phi 8 / 60$ & $\mathrm{C} 13$ & $\Phi 10 / 60$ & $\mathrm{C} 24$ & $\Phi 12 / 60$ \\
\hline $\mathrm{C} 3$ & & & & $\Phi 8 / 70$ & C14 & $\Phi 10 / 70$ & $\mathrm{C} 25$ & $\Phi 12 / 70$ \\
\hline $\mathrm{C} 4$ & & & & Ф8/80 & $\mathrm{C} 15$ & $\Phi 10 / 80$ & C26 & $\Phi 12 / 80$ \\
\hline C5 & & & & $\Phi 8 / 90$ & C16 & $\Phi 10 / 90$ & $\mathrm{C} 27$ & $\Phi 12 / 90$ \\
\hline C6 & & & & $\Phi 8 / 100$ & C17 & $\Phi 10 / 100$ & $\mathrm{C} 28$ & $\Phi 12 / 100$ \\
\hline C7 & & & & $\Phi 8 / 110$ & C18 & $\Phi 10 / 110$ & C29 & $\Phi 12 / 110$ \\
\hline $\mathrm{C} 8$ & & & & $\Phi 8 / 120$ & C19 & $\Phi 10 / 120$ & C30 & $\Phi 12 / 120$ \\
\hline C9 & & & & $\Phi 8 / 130$ & $\mathrm{C} 20$ & $\Phi 10 / 130$ & C31 & $\Phi 12 / 130$ \\
\hline $\mathrm{C} 10$ & & & & $\Phi 8 / 140$ & $\mathrm{C} 21$ & $\Phi 10 / 140$ & C32 & $\Phi 12 / 140$ \\
\hline $\mathrm{C} 11$ & & & & $\Phi 8 / 150$ & $\mathrm{C} 22$ & $\Phi 10 / 150$ & C33 & $\Phi 12 / 150$ \\
\hline
\end{tabular}

Farklı parametrelerde tasarlanan kolon modellerinde sargılı beton basınç dayanımları hesaplanarak gerilme-şekil değiştirme ilişkileri $(\sigma-\varepsilon)$ elde edilmiş ve elde edilen sonuçlar farklı parametrelere göre karşılaştırılarak yorumlanmıştır. Sarg1 donatı çapı ve sargı donatısı aralığının değişiminin betonarme kesitlerin davranışına etkisi Mander [8] ve TBDY [9] modeline göre incelenmiştir. 
Mander [8] ve TBDY [9] modelinden elde edilen sonuçlar Tablolar halinde karşılaştırmalı olarak verilerek yorumlanmıştır.

\section{Araştırma Bulguları ve Tartışma}

Mander [8] ve TBDY [9] modellerinden elde edilen sargılı beton basınç dayanımlarını karşılaştırmak amacı ile sayısal çalışmalar yapılmıştır. İncelenen kolon modellerinde farklı sargı donatısı çapı ve aralığına sahip betonarme kolon kesitleri Mander [8] ve TBDY'ye [9] göre sargılı beton basınç dayanımları ve birim şekil değiştirmeleri hesaplanmıştır. Farklı sargı donatı çapı ve aralığ1 için Mander [8] ve TBDY [9] modelleri kullanılarak beton gerilme birim şekil değiştirme grafikleri elde edilmiştir. Farklı modeller için yapılan hesap sonuçları Tablolar halinde özetlenmiştir.

Mander modeline göre sargılı betonda, basınç gerilmesi $\left(f_{c c}^{\prime}\right)$, sargılı beton basınç birim şekil değiştirmesinin $\left(\varepsilon_{c c}\right)$ fonksiyonu olarak farklı sargı donatı çapı ve sarg1 donatı aralığına göre elde edilen gerilme-şekil değiştirme ilişkileri Şekil 6'da özetlenmiştir. Mander [8] modeline göre tasarlanan kare en-kesitli kolon modellerinde hesaplanan çekirdek betonuna uygulanan etkili yanal basınç kuvveti $\left(f_{l}^{\prime}\right)$, sargılı beton basınç dayanımı $\left(f_{c c}^{\prime}\right)$, birim şekil değiştirmesi $\left(\varepsilon_{c c}\right)$ ve sargılı betonun maksimum birim şekil değiştirmesi $\left(\varepsilon_{c u}\right)$ elde edilmiş, Tablo 2'de özetlenmiştir. Tablo 2 'de sargılı betondan elde edilen değerlerin Mander modelinde sargısız beton için verilen gerilme ve şekil değiştirme sınırlarına oranı olarak verilmiştir.

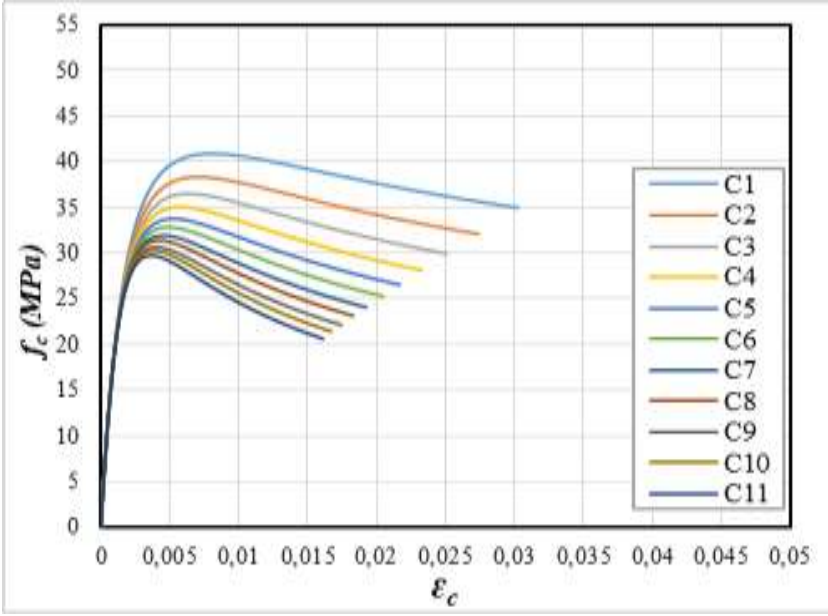

(a) Sarg1 donat1s1 $\Phi 8 \mathrm{~mm}$

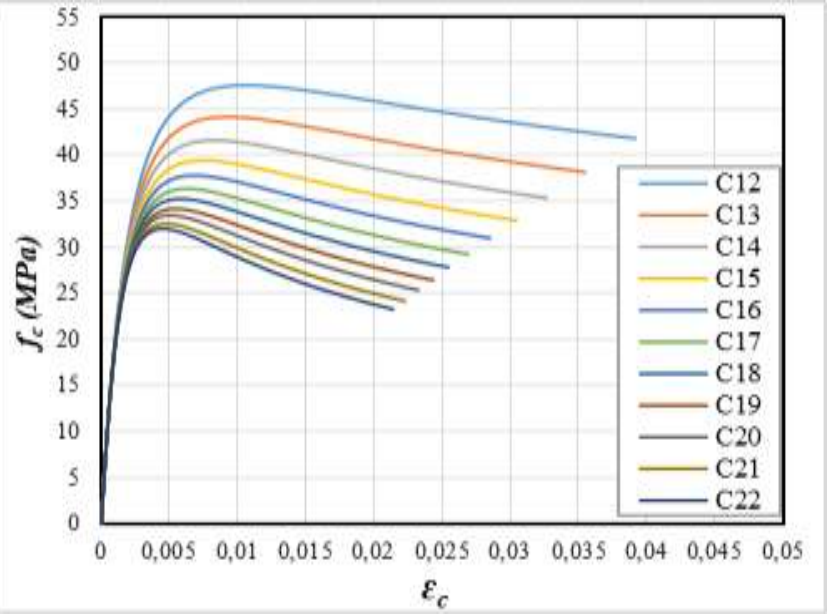

(b) Sarg1 donatis1 $\Phi 10 \mathrm{~mm}$

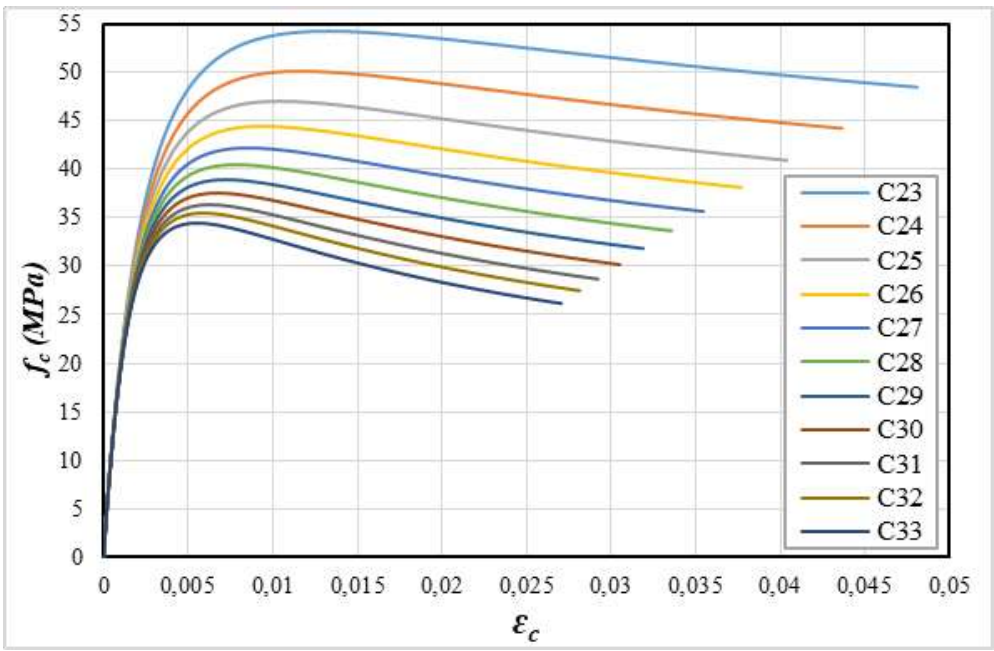

(c) Sarg1 donatis1 $\Phi 12 \mathrm{~mm}$

Şekil 6. Mander modeline göre elde edilen gerilme-şekil değiştirme grafikleri 
Tablo 2. Mander modeline göre kolon modellerinin hesap sonuçları

\begin{tabular}{|c|c|c|c|c|c|}
\hline No & Sargı Donatısı (mm) & $f_{l}^{\prime}(\mathbf{M P a})$ & $f_{c c}^{\prime} / \mathbf{0}, \mathbf{8 5} f_{c o}^{\prime}$ & $\varepsilon_{c c} / \varepsilon_{c o}$ & $\varepsilon_{c u} / 2 \varepsilon_{c o}$ \\
\hline $\mathrm{C} 1$ & $\Phi 8 / 50$ & 2.77 & 1.60 & 4.00 & 7.58 \\
\hline $\mathrm{C} 2$ & $\Phi 8 / 60$ & 2.23 & 1.51 & 3.55 & 6.83 \\
\hline $\mathrm{C} 3$ & $\Phi 8 / 70$ & 1.85 & 1.43 & 3.15 & 6.25 \\
\hline $\mathrm{C} 4$ & $\Phi 8 / 80$ & 1.57 & 1.37 & 2.85 & 5.80 \\
\hline $\mathrm{C} 5$ & $\Phi 8 / 90$ & 1.34 & 1.33 & 2.65 & 5.43 \\
\hline C6 & $\Phi 8 / 100$ & 1.17 & 1.29 & 2.45 & 5.10 \\
\hline C7 & $\Phi 8 / 110$ & 1.03 & 1.25 & 2.30 & 4.83 \\
\hline $\mathrm{C} 8$ & $\Phi 8 / 120$ & 0.91 & 1.23 & 2.15 & 4.58 \\
\hline C9 & $\Phi 8 / 130$ & 0.81 & 1.20 & 2.00 & 4.38 \\
\hline $\mathrm{C} 10$ & $\Phi 8 / 140$ & 0.72 & 1.18 & 1.90 & 4.18 \\
\hline $\mathrm{C} 11$ & $\Phi 8 / 150$ & 0.65 & 1.16 & 1.85 & 4.03 \\
\hline $\mathrm{C} 12$ & $\Phi 10 / 50$ & 4.34 & 1.86 & 5.30 & 9.80 \\
\hline $\mathrm{C} 13$ & $\Phi 10 / 60$ & 3.50 & 1.73 & 4.65 & 8.88 \\
\hline $\mathrm{C} 14$ & $\Phi 10 / 70$ & 2.91 & 1.63 & 4.15 & 8.18 \\
\hline $\mathrm{C} 15$ & $\Phi 10 / 80$ & 2.46 & 1.55 & 3.75 & 7.60 \\
\hline $\mathrm{C} 16$ & $\Phi 10 / 90$ & 2.11 & 1.48 & 3.40 & 7.13 \\
\hline $\mathrm{C} 17$ & $\Phi 10 / 100$ & 1.84 & 1.43 & 3.15 & 6.73 \\
\hline $\mathrm{C} 18$ & $\Phi 10 / 110$ & 1.61 & 1.38 & 2.90 & 6.38 \\
\hline $\mathrm{C} 19$ & $\Phi 10 / 120$ & 1.43 & 1.34 & 2.70 & 6.08 \\
\hline $\mathrm{C} 20$ & $\Phi 10 / 130$ & 1.27 & 1.31 & 2.55 & 5.80 \\
\hline $\mathrm{C} 21$ & $\Phi 10 / 140$ & 1.14 & 1.28 & 2.40 & 5.58 \\
\hline $\mathrm{C} 22$ & $\Phi 10 / 150$ & 1.02 & 1.25 & 2.25 & 5.35 \\
\hline $\mathrm{C} 23$ & $\Phi 12 / 50$ & 6.27 & 2.13 & 6.65 & 12.00 \\
\hline $\mathrm{C} 24$ & $\Phi 12 / 60$ & 5.06 & 1.97 & 5.85 & 10.93 \\
\hline $\mathrm{C} 25$ & $\Phi 12 / 70$ & 4.20 & 1.84 & 5.20 & 10.10 \\
\hline $\mathrm{C} 26$ & $\Phi 12 / 80$ & 3.56 & 1.74 & 4.70 & 9.43 \\
\hline $\mathrm{C} 27$ & $\Phi 12 / 90$ & 3.06 & 1.65 & 4.30 & 8.88 \\
\hline $\mathrm{C} 28$ & $\Phi 12 / 100$ & 2.66 & 1.58 & 3.95 & 8.40 \\
\hline $\mathrm{C} 29$ & $\Phi 12 / 110$ & 2.33 & 1.53 & 3.65 & 7.98 \\
\hline $\mathrm{C} 30$ & $\Phi 12 / 120$ & 2.07 & 1.47 & 3.35 & 7.63 \\
\hline $\mathrm{C} 31$ & $\Phi 12 / 130$ & 1.84 & 1.43 & 3.15 & 7.30 \\
\hline $\mathrm{C} 32$ & $\Phi 12 / 140$ & 1.65 & 1.39 & 2.95 & 7.03 \\
\hline C33 & $\Phi 12 / 150$ & 1.48 & 1.35 & 2.75 & 6.78 \\
\hline
\end{tabular}

TBDY'ye [9] göre elde edilen $\sigma-\varepsilon$ grafikleri farklı sargı donatı çapı ve sargı donatı aralığına göre Şekil 7'de özetlenmiştir. TBDY'ye [9] göre tasarlanan kare kolon modellerinde hesaplanan betona uygulanan etkili yanal basınç kuvveti $\left(f_{e}\right)$, sargılı beton basınç dayanımı $\left(f_{c c}\right)$, birim şekil değiştirmesi $\left(\varepsilon_{c c}\right)$ ve sargılı betonun maksimum birim şekil değiştirmesi $\left(\varepsilon_{c u}\right)$ elde edilmiştir (Tablo $3)$. 


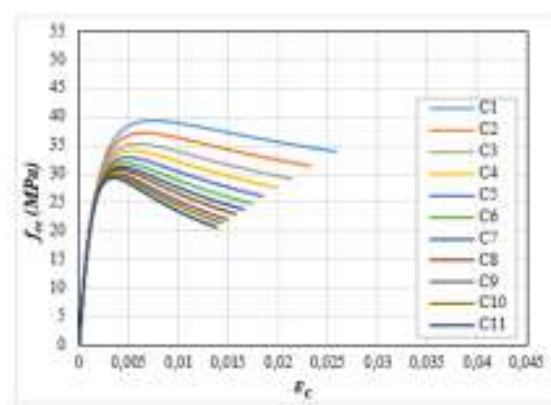

(a) Sarg1 donatıs1 $\Phi 8 \mathrm{~mm}$

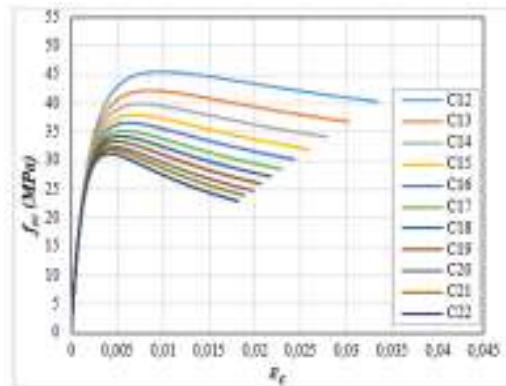

(b) Sarg1 donatısı $\Phi 10 \mathrm{~mm}$

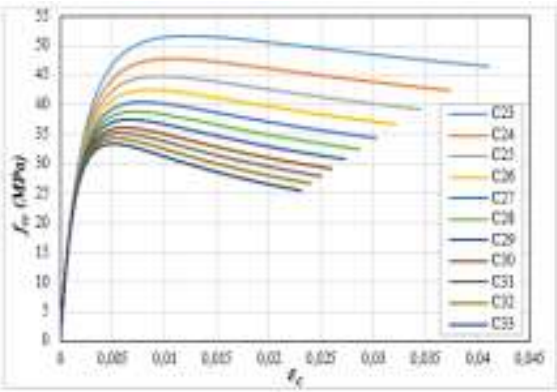

(c) Sarg1 donatıs1 $\Phi 12 \mathrm{~mm}$

Şekil 7. TBDY'ye göre elde edilen gerilme-şekil değiştirme grafikleri

Tablo 3. TBDY’ye göre kolon modellerinin hesap sonuçları

\begin{tabular}{|c|c|c|c|c|c|}
\hline No & Sargı Donatısı (mm) & $f_{e}(\mathrm{MPa})$ & $f_{c c} / 0,85 f_{c o}$ & $\varepsilon_{c c} / \varepsilon_{c o}$ & $\varepsilon_{c u} / 2 \varepsilon_{c o}$ \\
\hline $\mathrm{C} 1$ & $\Phi 8 / 50$ & 2.44 & 1.55 & 3.75 & 7.37 \\
\hline $\mathrm{C} 2$ & $\Phi 8 / 60$ & 1.97 & 1.45 & 3.30 & 6.66 \\
\hline $\mathrm{C} 3$ & $\Phi 8 / 70$ & 1.63 & 1.39 & 2.95 & 6.11 \\
\hline $\mathrm{C} 4$ & $\Phi 8 / 80$ & 1.38 & 1.33 & 2.65 & 5.66 \\
\hline $\mathrm{C} 5$ & $\Phi 8 / 90$ & 1.19 & 1.29 & 2.45 & 5.29 \\
\hline $\mathrm{C} 6$ & $\Phi 8 / 100$ & 1.03 & 1.25 & 2.30 & 4.97 \\
\hline $\mathrm{C} 7$ & $\Phi 8 / 110$ & 0.90 & 1.23 & 2.15 & 4.71 \\
\hline $\mathrm{C} 8$ & $\Phi 8 / 120$ & 0.80 & 1.20 & 2.00 & 4.49 \\
\hline $\mathrm{C} 9$ & $\Phi 8 / 130$ & 0.71 & 1.18 & 1.90 & 4.29 \\
\hline $\mathrm{C} 10$ & $\Phi 8 / 140$ & 0.63 & 1.16 & 1.80 & 4.11 \\
\hline $\mathrm{C} 11$ & $\Phi 8 / 150$ & 0.57 & 1.15 & 1.75 & 3.94 \\
\hline $\mathrm{C} 12$ & $\Phi 10 / 50$ & 3.82 & 1.78 & 4.90 & 9.54 \\
\hline $\mathrm{C} 13$ & $\Phi 10 / 60$ & 3.08 & 1.66 & 4.30 & 8.66 \\
\hline $\mathrm{C} 14$ & $\Phi 10 / 70$ & 2.55 & 1.56 & 3.85 & 7.97 \\
\hline $\mathrm{C} 15$ & $\Phi 10 / 80$ & 2.16 & 1.49 & 3.45 & 7.43 \\
\hline $\mathrm{C} 16$ & $\Phi 10 / 90$ & 1.85 & 1.43 & 3.15 & 6.94 \\
\hline $\mathrm{C} 17$ & $\Phi 10 / 100$ & 1.61 & 1.38 & 2.90 & 6.57 \\
\hline C18 & $\Phi 10 / 110$ & 1.41 & 1.34 & 2.70 & 6.23 \\
\hline C19 & $\Phi 10 / 120$ & 1.25 & 1.31 & 2.50 & 5.91 \\
\hline $\mathrm{C} 20$ & $\Phi 10 / 130$ & 1.11 & 1.27 & 2.35 & 5.66 \\
\hline $\mathrm{C} 21$ & $\Phi 10 / 140$ & 0.99 & 1.25 & 2.25 & 5.43 \\
\hline $\mathrm{C} 22$ & $\Phi 10 / 150$ & 0.89 & 1.22 & 2.10 & 5.23 \\
\hline $\mathrm{C} 23$ & $\Phi 12 / 50$ & 5.49 & 2.02 & 6.15 & 11.71 \\
\hline $\mathrm{C} 24$ & $\Phi 12 / 60$ & 4.43 & 1.87 & 5.40 & 10.66 \\
\hline $\mathrm{C} 25$ & $\Phi 12 / 70$ & 3.67 & 1.76 & 4.80 & 9.86 \\
\hline $\mathrm{C} 26$ & $\Phi 12 / 80$ & 3.11 & 1.66 & 4.30 & 9.20 \\
\hline $\mathrm{C} 27$ & $\Phi 12 / 90$ & 2.67 & 1.59 & 3.95 & 8.66 \\
\hline $\mathrm{C} 28$ & $\Phi 12 / 100$ & 2.32 & 1.52 & 3.60 & 8.17 \\
\hline $\mathrm{C} 29$ & $\Phi 12 / 110$ & 2.03 & 1.47 & 3.35 & 7.77 \\
\hline $\mathrm{C} 30$ & $\Phi 12 / 120$ & 1.80 & 1.42 & 3.10 & 7.43 \\
\hline $\mathrm{C} 31$ & $\Phi 12 / 130$ & 1.60 & 1.38 & 2.90 & 7.11 \\
\hline $\mathrm{C} 32$ & $\Phi 12 / 140$ & 1.43 & 1.35 & 2.70 & 6.83 \\
\hline $\mathrm{C} 33$ & $\Phi 12 / 150$ & 1.29 & 1.31 & 2.55 & 6.57 \\
\hline
\end{tabular}

Kare en-kesitli betonarme kolon modellerinde Mander [8] ve TBDY [9] modellerine göre hesaplanan sargılı beton dayanımı ve birim şekil değiştirme değerleri karşılaştırmalı olarak Tablo 4 'te verilmiştir. Kare en-kesitli betonarme kolonların Mander [8] ve TBDY [9] modellerine göre gerilme-ş̧ekil değiştirme grafiklerinin karşılaştırılması Şekil 8'de verilmiş̧ir. 
Tablo 4. Farklı sargılı beton modellerine göre hesaplanan sonuç değerlerinin karşılaştırması

\begin{tabular}{|c|c|c|c|c|c|c|c|c|c|}
\hline \multirow{2}{*}{ No } & \multicolumn{2}{|c|}{ Mander Modeli } & \multicolumn{2}{|c|}{ TBDY (2018) } & \multirow{2}{*}{ No } & \multicolumn{2}{|c|}{ Mander modeli } & \multicolumn{2}{|c|}{ TBDY (2018) } \\
\hline & ${f^{\prime}}_{l}(\mathbf{M P a})$ & $\begin{array}{l}f_{c c}^{\prime} \\
/ 0.85 f_{c o}^{\prime}\end{array}$ & $f_{e}(M P a)$ & $\begin{array}{l}f_{c c} \\
/ 0.85 f_{c o}\end{array}$ & & $\begin{array}{l}\varepsilon_{c c} \\
/ \varepsilon_{c o}\end{array}$ & $\begin{array}{l}\varepsilon_{c u} \\
/ 2 \varepsilon_{c o}\end{array}$ & $\begin{array}{l}\varepsilon_{c c} \\
/ \varepsilon_{c o}\end{array}$ & $\varepsilon_{c u} / 2 \varepsilon_{c o}$ \\
\hline $\mathrm{C} 1$ & 2.77 & 1.60 & 2.44 & 1.55 & $\mathrm{C} 1$ & 4.00 & 7.58 & 3.75 & 7.37 \\
\hline $\mathrm{C} 2$ & 2.23 & 1.51 & 1.97 & 1.45 & $\mathrm{C} 2$ & 3.55 & 6.83 & 3.30 & 6.66 \\
\hline $\mathrm{C} 3$ & 1.85 & 1.43 & 1.63 & 1.39 & C3 & 3.15 & 6.25 & 2.95 & 6.11 \\
\hline $\mathrm{C} 4$ & 1.57 & 1.37 & 1.38 & 1.33 & $\mathrm{C} 4$ & 2.85 & 5.80 & 2.65 & 5.66 \\
\hline $\mathrm{C} 5$ & 1.34 & 1.33 & 1.19 & 1.29 & $\mathrm{C} 5$ & 2.65 & 5.43 & 2.45 & 5.29 \\
\hline C6 & 1.17 & 1.29 & 1.03 & 1.25 & C6 & 2.45 & 5.10 & 2.30 & 4.97 \\
\hline $\mathrm{C} 7$ & 1.03 & 1.25 & 0.90 & 1.23 & $\mathrm{C} 7$ & 2.30 & 4.83 & 2.15 & 4.71 \\
\hline $\mathrm{C} 8$ & 0.91 & 1.23 & 0.80 & 1.20 & $\mathrm{C} 8$ & 2.15 & 4.58 & 2.00 & 4.49 \\
\hline $\mathrm{C} 9$ & 0.81 & 1.20 & 0.71 & 1.18 & $\mathrm{C} 9$ & 2.00 & 4.38 & 1.90 & 4.29 \\
\hline $\mathrm{C} 10$ & 0.72 & 1.18 & 0.63 & 1.16 & $\mathrm{C} 10$ & 1.90 & 4.18 & 1.80 & 4.11 \\
\hline $\mathrm{C} 11$ & 0.65 & 1.16 & 0.57 & 1.15 & $\mathrm{C} 11$ & 1.85 & 4.03 & 1.75 & 3.94 \\
\hline $\mathrm{C} 12$ & 4.34 & 1.86 & 3.82 & 1.78 & $\mathrm{C} 12$ & 5.30 & 9.80 & 4.90 & 9.54 \\
\hline $\mathrm{C} 13$ & 3.50 & 1.73 & 3.08 & 1.66 & C13 & 4.65 & 8.88 & 4.30 & 8.66 \\
\hline C14 & 2.91 & 1.63 & 2.55 & 1.56 & C14 & 4.15 & 8.18 & 3.85 & 7.97 \\
\hline C15 & 2.46 & 1.55 & 2.16 & 1.49 & C15 & 3.75 & 7.60 & 3.45 & 7.43 \\
\hline C16 & 2.11 & 1.48 & 1.85 & 1.43 & C16 & 3.40 & 7.13 & 3.15 & 6.94 \\
\hline C17 & 1.84 & 1.43 & 1.61 & 1.38 & C17 & 3.15 & 6.73 & 2.90 & 6.57 \\
\hline $\mathrm{C} 18$ & 1.61 & 1.38 & 1.41 & 1.34 & C18 & 2.90 & 6.38 & 2.70 & 6.23 \\
\hline C19 & 1.43 & 1.34 & 1.25 & 1.31 & C19 & 2.70 & 6.08 & 2.50 & 5.91 \\
\hline $\mathrm{C} 20$ & 1.27 & 1.31 & 1.11 & 1.27 & $\mathrm{C} 20$ & 2.55 & 5.80 & 2.35 & 5.66 \\
\hline $\mathrm{C} 21$ & 1.14 & 1.28 & 0.99 & 1.25 & $\mathrm{C} 21$ & 2.40 & 5.58 & 2.25 & 5.43 \\
\hline $\mathrm{C} 22$ & 1.02 & 1.25 & 0.89 & 1.22 & $\mathrm{C} 22$ & 2.25 & 5.35 & 2.10 & 5.23 \\
\hline $\mathrm{C} 23$ & 6.27 & 2.13 & 5.49 & 2.02 & $\mathrm{C} 23$ & 6.65 & 12.00 & 6.15 & 11.71 \\
\hline C24 & 5.06 & 1.97 & 4.43 & 1.87 & $\mathrm{C} 24$ & 5.85 & 10.93 & 5.40 & 10.66 \\
\hline $\mathrm{C} 25$ & 4.20 & 1.84 & 3.67 & 1.76 & $\mathrm{C} 25$ & 5.20 & 10.10 & 4.80 & 9.86 \\
\hline C26 & 3.56 & 1.74 & 3.11 & 1.66 & $\mathrm{C} 26$ & 4.70 & 9.43 & 4.30 & 9.20 \\
\hline $\mathrm{C} 27$ & 3.06 & 1.65 & 2.67 & 1.59 & $\mathrm{C} 27$ & 4.30 & 8.88 & 3.95 & 8.66 \\
\hline $\mathrm{C} 28$ & 2.66 & 1.58 & 2.32 & 1.52 & $\mathrm{C} 28$ & 3.95 & 8.40 & 3.60 & 8.17 \\
\hline C29 & 2.33 & 1.53 & 2.03 & 1.47 & $\mathrm{C} 29$ & 3.65 & 7.98 & 3.35 & 7.77 \\
\hline C30 & 2.07 & 1.47 & 1.80 & 1.42 & C30 & 3.35 & 7.63 & 3.10 & 7.43 \\
\hline C 31 & 1.84 & 1.43 & 1.60 & 1.38 & C31 & 3.15 & 7.30 & 2.90 & 7.11 \\
\hline C32 & 1.65 & 1.39 & 1.43 & 1.35 & C32 & 2.95 & 7.03 & 2.70 & 6.83 \\
\hline $\mathrm{C} 33$ & 1.48 & 1.35 & 1.29 & 1.31 & C33 & 2.75 & 6.78 & 2.55 & 6.57 \\
\hline
\end{tabular}



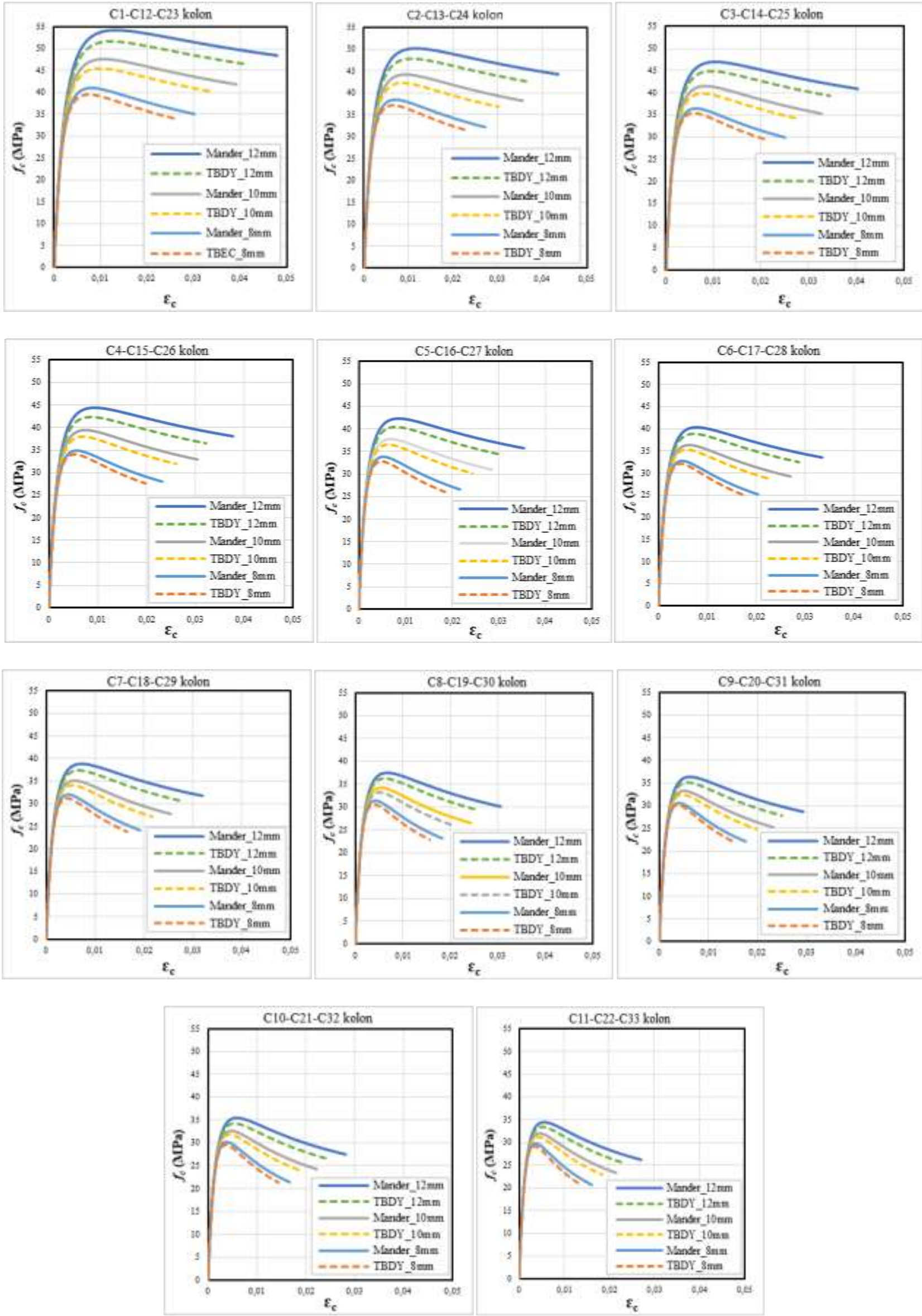

Şekil 8. Mander ve TBDY (2018) ve modellerine göre gerilme-şekil değiştirme grafiklerinin karşılaştırılması (sargı donatısı: $\Phi 8 \mathrm{~mm}, 10 \mathrm{~mm}, 12 \mathrm{~mm}$ ) 


\section{Sonuçlar}

Farklı sargı donatısı çapı ve aralığına göre tasarlanan betonarme kolon modellerinin TBDY (2018) ve Mander (1988) modellerine göre hesaplanan sargılı beton dayanımı ve maksimum gerilmeye karşı gelen birim kısalma değerlerinin farklı olduğu sonucu elde edilmiştir. Tasarlanan kolon kesitlerinden elde edilen sonuçlar aşağıda özetlenmiştir.

Kare en-kesitli betonarme kolon modellerinde sargı donatısı aralığı sabit iken sargı donatı çapının artması ile sargılı beton modellerine göre hesaplanan sargılı beton basınç dayanımlarının arasındaki farkların artmakta olduğu sonucu elde edilmiştir. Sarg1 donatı çapının artması ile sargılı beton modellerine göre hesaplanan sarg1 etkinlik katsayısı ve betona uygulanan basınç dayanımları da artmakta fakat sargı donatı aralığının artması ile bahsi geçen parametrelerin değerleri azalmaktadır. Sarg1 donatı aralığının artması ile sargılı beton modellerinden elde edilen sargılı beton basınç dayanımları azalmaktadır. Sargı donatı aralığının artması ile hesaplanan sargı etkinlik katsayısının karşılaştırmasından, Mander modeline göre hesaplanan değerler TBDY (2018)'e göre elde edilen değerlerden daha fazladır. Sargılı beton basınç dayanımlarının karşılaştırmasından görüleceği gibi Mander modelinden elde edilen değerler TBDY (2018)'e modelinden elde edilen değerlerden daha fazladır. Tablolarda yapılan karşılaştırmalardan görüleceği gibi sargı donatı aralığının artması ile farklı modellerden elde edilen sargılı beton basınç dayanımlarının arasındaki farklılıklar azalmaktadır. Sargı donatı çapının ve sargı donatı aralığının; sargı etkinlik katsayısı, sargılı beton basınç dayanımı ve kesit sünekliği üzerinde etkili olduğu görülmüştür. Modellerde farklı çaplarda ve aralıklarda sarg1 donatısı kullanımının, farklı parametrelerde tasarlanan betonarme kolon kesitlerinin sargı etkinlik katsayı, betona uygulanan etkili yanal basınç ve sargılı beton basınç dayanımlarını etkilediği sonucu elde edilmiştir.

\section{Kaynaklar}

[1]. Yüksel, S.B. ve Foroughi, S., Betonarme Kolonların Sargısız ve Sargılı Beton Dayanımının Analitik Olarak Araştırılması, Konya Mühendislik Bilimleri Dergisi, 2019a, 7(3): 611-629.

[2]. Haytham, F., Isleem, H.F., Wang, D. and Wang, Z., No AccessAxial stress-strain model for square concrete columns internally confined with GFRP hoops, Magazine of Concrete Research, 2018, 70(20): 1064-1079.

[3]. Campione, G. and Fossetti, M., Compressive behaviour of concrete elliptical columns confined by single hoops," Engineering Structures, 2007, 29(3): 408-417.

[4]. Binici, B., An analytical model for stress-strain behavior of confined concrete, Engineering Structures, 2005, 27(7): 1040-1051.

[5]. Dong, C.X., Kwan, A.K.H. and Ho, J.C.M., Effects of confining stiffness and rupture strain on performance of FRP confined concrete, Engineering Structures, 2015, 97: 1-14.

[6]. Colajanni, P., Papia, M. and Spinella, N., Stress-Strain Law for Confined Concrete with Hardening or Softening Behavior, Hindawi Publishing Corporation, Advances in Civil Engineering, 2013.

[7]. Foroughi, S., Jamal, R., Yüksel, S. B., Sargı Donatısı ve Eksenel Yük Seviyesinin Betonarme Kolonların Eğrilik Süneklik ile Etkin Kesit Rijitliğe Etkisi, ElCezerî Fen ve Mühendislik Dergisi, 2020, 7 (3); 1309-1319.

[8]. Mander, J. B., Priestley, M. J. N. and Park, R., Theoretical stress-strain model for confined concrete, Journal of Structural Engineering, 1988, 114(8): 1804-1826.

[9]. TBDY., Türkiye Bina Deprem Yönetmeliği, T.C. Bayındırlık ve İskân Bakanlığı, 2018, Ankara, Türkiye.

[10]. Foroughi, S., Sargılı ve Sargısız Betonarme Elemanların Davranışlarının Gerilme-Şekil Değiştirme Modellerinin Araştırılması, Doktora Semineri, Selçuk Üniversitesi, Fen Bilimleri Enstitüsü, 2018, Konya / Türkiye. 
[11]. Yüksel, S. B. ve Foroughi, S., Kare Kesitli Betonarme Kolonların Çekirdek Bölgesinin Gerilme-Şekil Değiştirme Davranışının Analitik Olarak Araştırılması, 2nd International Congress on Engineering and Architecture (ENAR-2019), 2019b, p. 465-486, Marmaris / Turkey.

[12]. Saatçioğlu, M. and Ravzi, S. R., Strength and ductility of confined concrete, Journal of Structural Engineering, 1992, 118(6): 1590-1607. 